\title{
GIANT CONGENITAL DIVERTICULA AND NEONATAL RUPTURE OF COLON: A CASE ASSOCIATED WITH TRUE CONGENITAL PARTIAL HYPERTROPHY OF THE CROSSED TYPE
}

\author{
BY
}

\author{
J. EDGAR MORISON, M.D., B.Sc.
}

\author{
(From the Department of Pathology, Queen's University, Belfast, N. Ireland)
}

True diverticula of the colon are of considerable morphological interest and the occurrence in a new-born child of two large cystic diverticula in the pelvic colon, and the rupture of the bowel opposite one of them, appears unique and capable of providing some information as to their significance.

\section{Case record}

Clinical history. The patient died on the twelfth day of life, having been delivered by a Caesarian operation for disproportion. He was difficult to resuscitate at birth and the abdomen always appeared distended. This distension varied somewhat, but there were no other unusual symptoms until he suddenly collapsed and died in two hours.

Post-mortem examination. The body was that of a well-nourished male infant. The left side of the cranium and face, especially the mandible and ear, was larger than the right. This asymmetry was less marked posteriorly. No certain difference could be detected in the arms, thorax or abdomen, but the left leg was $2 \mathrm{~cm}$. shorter than the right and this was largely accounted for by the shortening of the femur. The thickness of the thigh was proportionately altered, but asymmetry of the feet was not detected. On opening the cranium the left anterior and middle fossae of the skull were obviously larger than the right, but the disporportion between the posterior fossae was less certain. The cerebral convolutions were normal, but the cerebrum and even the cerebellum and pons shared in the asymmetry of the skull. No asymmetry of the thoracic or abdominal organs was demonstrable.

Except for the pelvic colon the contents of the thorax and abdomen were normal. The colon had a long free mesentery and lying in it, and slightly behind the bowel and almost $7 \mathrm{~cm}$. from the anus, there was a cystic cavity $4 \mathrm{~cm}$. from side to side, $3.5 \mathrm{~cm}$. from above downwards and $2 \mathrm{~cm}$. from front to back (fig. 1). This communicated with the lumen of the bowel by an orifice $1.2 \mathrm{~cm}$. by $0.5 \mathrm{~cm}$. in diameter. Its walls were 2 to $3 \mathrm{~mm}$. thick, but showed no condensation of muscle into bands. Beginning $4.5 \mathrm{~cm}$. above this opening and extending for $3.0 \mathrm{~cm}$. the mesenteric wall of the bowel was expanded into a similar cavity with thick walls. Both diverticula received their blood supply from the arcade of the inferior mesenteric artery. The superior cavity extended $1.0 \mathrm{~cm}$. above and $1.5 \mathrm{~cm}$. below its wide entrance, and when it was dilated the part below the opening was capable of compressing the adjacent bowel and producing obstruction. Immediately opposite this upper aneurysmal like

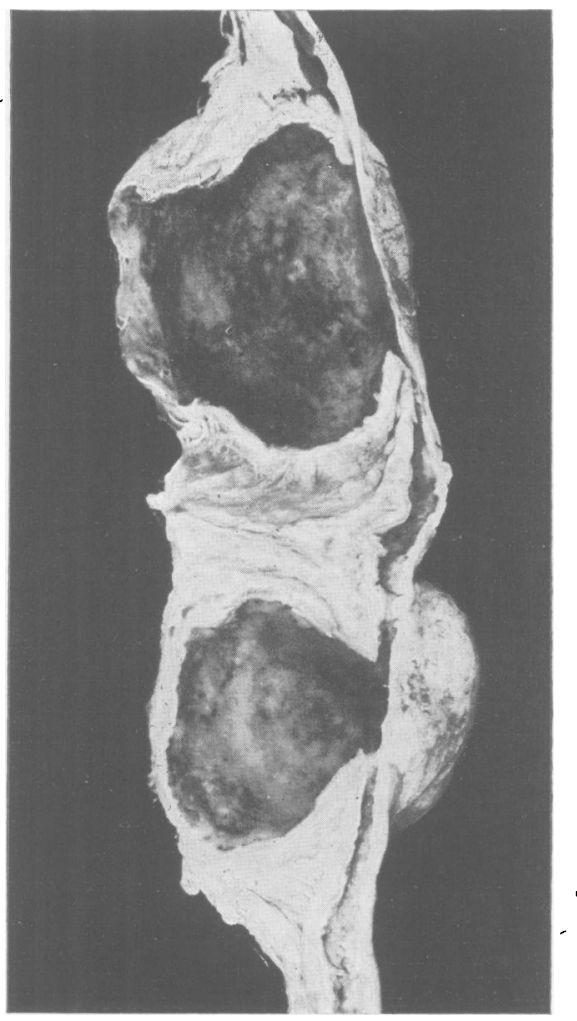

Fig. 1.-The two diverticula in the mesentery of the long pelvic colon. $\frac{3}{4}$ natural size.

swelling the anti-mesenteric wall of the bowel was thinned out over three localized areas. These were 3 to $6 \mathrm{~mm}$. in diameter, they did not bulge outwards; but through the largest a small perforation had occurred.

Histological examination. Sections from the wall of the diverticula showed greatly hypertrophied 
smooth muscle. There was some attempt at an arrangement of this into two layers with large prominent nerve cells between them, but often the layers intermingled. The lining consisted of acini of mucus producing cells, and deep to these a few small aggregates of lymphocytes and a well-defined layer of submucous muscle. Sections through the thin areas in the wall opposite the upper diverticulum showed the defect to consist of a relatively abrupt disappearance of both muscle layers (fig. 2). The outside it. Diverticula retain a communication with the lumen, while aggregates remaining isolated from the lumen form enterogenous cysts. Response to pathological stimuli or the proliferation of heterotopic epithelium explains any difference in the epithelium from that in the gut. This theory is elaborated with many illustrations by Evans (1929-30). It is best able to explain the present case. However, only in one embryo is there a record

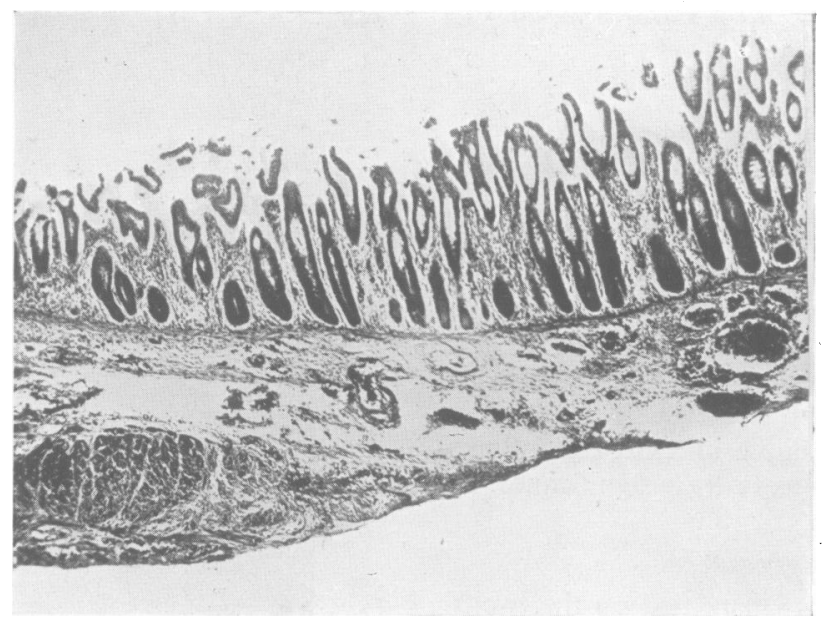

FIG. 2.-The longitudinal and circular muscle are deficient and the submucosa lies next the serosa near the site of the rupture. $\times 34$.

submucous muscle was preserved and the mucous glands did not penetrate more deeply than normal, but there was a rather diffuse increase in lymphoid tissue. There were small aggregates of polymorphs and patches of necrosis in the oedematous wall near these defects and some fibrin lay in the wall and on the serosal surfaces.

A complete histological examination of the other organs revealed little of relevant interest and the final anatomical summary read:-

Two true giant diverticula mesenteric border of pelvic colon. Focal areas of congenital absence of muscle opposite upper diverticulum. Perforation. Generalized peritonitis. True congenital partial hypertrophy of crossed type. Congenital patency of interventricular septum. Gross aspiration of liquor amnii. Patchy atelectasis.

\section{Discussion}

An early explanation offered by Roth (1881) for true congenital diverticula was that they represented a Meckel's diverticulum. Some diverticula may originate in this way, and even a diverticulum lying within the layers of the mesentery might be explained by abnormal fixation early in growth. The theory is difficult to accept when a diverticulum lies below the caecum or when there are several diverticula.

Lewis and Thyng (1907-8) described in pig, rabbit and human embryos, chiefly of 5.5 to $32 \mathrm{~mm}$. size, proliferations of the epithelial cells of the gut forming small cystic aggregates isolated from the lumen or communicating with it. Later many of these again become incorporated in the lumen, but some may come to lie in the wall of the intestine or of such an epithelial proliferation in the large intestine, and that was near the caecum in a $32 \mathrm{~mm}$. pig embryo. There are correspondingly very few reports of diverticula or cysts in the large bowel though the case described by Wright (1919-20) of a large diverticulum in the mesosigmoid of an adult may be compared with the present one.

Boikan (1930) in a discussion of meconium peritonitis and rupture of the gut in the newborn, in the absence of strangulation, cysts or diverticula, emphasized the occurrence of defects in the muscle associated with localized proliferation of lymphoid tissue and with a deeper penetration of mucous gland acini into the wall than usual. Lattes (1943) also emphasized lymphoid hyperplasia and abnormally deep glands in the ileum in a case of foetal perforation with pseudomyxoma peritonei. Boikan believed that the epithelial proliferations described by Lewis and Thyng determined a localized proliferation of lymphoid cells with disappearance of muscle elements. In the present case there was slight prominence of lymphoid cells, but no anomaly of the mucosa or of the submucosal muscle at the site of the defect. There may have been considerable disturbance in the development of the muscle adjacent to the large diverticulum from some other cause. It is important, however, to recognize that post-natal rupture of the bowel or pre-natal meconium peritonitis may result from some such localized defect in the muscle of the wall. Experimentally it is difficult to rupture the bowel of normal infants at post mortem. Unless there is interference with the blood supply from strangulation some such defect, 
however brought about, must be excluded before trauma is considered. It will often be masked by the early onset of post-mortem necrosis.

True hypertrophy is distinguished from false by the involvement of the bones and the classification is discussed by Stoesser (1928). A congenital partial hemihypertrophy involves a part of one side only. But if, for example, an arm on one side and a leg on the other are involved the condition is described as a congenital partial hypertrophy of the crossed type. The present case belongs to this group as did six of the thirty cases of partial hypertrophy reviewed by Gesell (1921). In some cases the whole of one side including the paired viscera is involved and the condition is described as a total hemihypertrophy. Gesell endeavours to interpret cases of hemihypertrophy as examples of asymmetry due to deviation in the normal process of twinning at an early stage. The possibility of incomplete twinning with duplicity of only one organ is sometimes advanced as a basis for intestinal tract anomalies (Bland-Sutton, 1919-20; Edwards, 192930). No such considerations appear relevant to the present case where there are two distinct diverticula, nor does any theory of twinning adequately explain cases of the crossed type of hypertrophy.

\section{Summary}

Two large cystic diverticula occurred in the pelvic colon of a twelve-day old infant and perforation occurred through a muscle defect opposite the upper one. These findings and an associated true congenital partial hypertrophy of the crossed type are discussed.

Thanks are due to Mr. H. C. Lowry for permission to record this case, to Professor J. H. Biggart for his advice and to Mr. D. McA. Mehaffey for the photographs.

\section{REFERENCES}

Bland-Sutton, J. (1919-20). Proc. roy. Soc. Med., 13, 128.

Boikan, W. S. (1930). Arch. Path., 9, 1164.

Edwards, H. (1929-30). Brit. J. Surg., 17, 7.

Evans, A. (1929-30). Loc. cit., 34.

Gesell, A. (1921). Arch. Neurol. Psychiat., 6, 400.

Lattes, R. (1943). Amer. J. Obstet. Gynec., 46, 149.

Lewis, F. T., and Thyng, F. W. (1907-8). Amer. J. Anat. 7, 505 .

Roth, M. (1881). Virchows Arch., 86, 371.

Stoesser, A. V. (1928). Amer. J. Dis. Child., 35, 885.

Wright, G. (1919-20). Proc. roy. Soc. Med., 13, 119. 